American Journal of Pharmacology and Toxicology 5 (3): 133-138, 2010

ISSN 1557-4962

(C) 2010 Science Publications

\title{
Characterization of Epoxidized and Non-Epoxidized Fatty Diethanolamides by High Performance Liquid Chromatography and Gas Chromatography
}

\author{
${ }^{1}$ Choy Sin Lee and ${ }^{2}$ Song Cang Lee \\ ${ }^{1}$ Department of Pharmaceutical Chemistry, School of Pharmacy, \\ International Medical University, No 126, Jalan 19/155B, Bukit Jalil, \\ 57000, Kuala Lumpur, Malaysia \\ ${ }^{2}$ Department of Biomedical Engineering, Faculty of Engineering, \\ University of Malaya, Lembah Pantai 50603 Kuala Lumpur, Malaysia
}

\begin{abstract}
Problem statement: This study was carried out for the characterization of epoxidized and non-epoxidized fatty diethanolamides by High Performance Liquid Chromatography (HPLC) and Gas Chromatography (GC). Approach: The fatty diethanolamides were synthesized by reacting $40 \%$ $(\mathrm{w} / \mathrm{w})$ of Epoxidized Palm Olein $\left(\mathrm{EPO}_{\mathrm{o}}\right)$ with $60 \%(\mathrm{w} / \mathrm{w})$ Refined Bleached Deodorized Plam Kernel Olein $\left(\mathrm{RBDPKO}_{\mathrm{o}}\right)$ with Diethanolamine (DEA) at $110^{\circ} \mathrm{C}$ for $5 \mathrm{~h}$. Results: The identities of the peaks were established by secondary standards that were derived from pure methyl esters. HPLC separated major non-epoxidized diethanolamide compounds, namely $\mathrm{C}_{10: 0}, \mathrm{C}_{12: 0}, \mathrm{C}_{14: 0}, \mathrm{C}_{16: 0}, \mathrm{C}_{18: 1}$ and $\mathrm{C}_{18: 0}$ and the molecular weights of the compounds were dentified by Liquid Chromatography-Mass Spectrometry (LC-MS). Conclusion: GC provided a more complete separation for the non-epoxidized diethanolamides, epoxidized diethanolamides, glycerol, Diethanolamine (DEA) and some minor compounds from the self-condensation of DEA and diethanolamides. Gas Chromatography-Mass Spectrometry (GC-MS) elucidated the chemical structure of the epoxidized diethanolamides.
\end{abstract}

Key words: Diethanolamides, gas chromatography, gas chromatography-mass spectrometry, high performance liquid chromatography, liquid chromatography-mass spectrometry

\section{INTRODUCTION}

Reaction of fatty acids or fatty acid methyl esters with alkanolamine produces fatty alkanolamides, such as monoalkanolamide and dialkanolamide (Shapiro, 1968). Fatty alkanolamides were prepared by reacting animal or vegetable-based triacylglycerols with different classes of alkanolamines, such as ethanolamine and diethanolamine (Feairheller et al., 1994; Kolancilar, 2004). The fatty alkanolamides are versatile oleochemicals that usually used as non-ionic surfactant in cosmetic, personal care and house-hold products. Besides, they can also be used as polyols for the production of rigid polyurethane foams. The fatty alkanolamides for polyurethane were prepared by reacting natural oils and fats, i.e., tallow, soybean, linseed, peanut, safflower oil and palm oil with alkanolamines at elevated temperature (Khoe et al., 1973; Khoe and Frankel, 1976; Badri et al., 2004; Rahman et al., 2003; Lee et al., 2007; Bononi and Tateo, 2007). As the world progress, the industries are paying more attention to produce polyols from vegetable oil considering that petroleum is diminishing rapidly. Epoxidized diethanolamides as starting material of rigid polyurethane foam were prepared from epoxidized palm olein (Lee et al., 2009)

In this study, fatty diethanolamides were synthesized from the mixture of Refined Bleached Deodorized Palm Kernel Olein $\left(\mathrm{RBDPKO}_{\mathrm{o}}\right)$ and Epoxidized Palm Olein $\left(\mathrm{EPO}_{\mathrm{o}}\right)$ with Diethanolamine (DEA) reagent. The synthesized diethanolamides were mixture of epoxidized and non-epoxidized fatty acid diethanolamides ranging from $\mathrm{C}_{8}-\mathrm{C}_{20}$ (Fig. 1). The epoxides in fatty diethanolamides provide additional cross-linking sites by forming oxazolidone linkages in the polyurethane network and improved the properties of the rigid polyurethane foam, in terms of thermal and chemical properties (Lee et al., 2007).

The potential of these fatty diethanolamides are no doubt noticeable and to prepare the production of these fatty diethanolamides in plant scale, a reliable method for the analysis and characterization of the fatty diethanolamides is needed, for the purpose of process development and quality control.

Corresponding Author: Choy Sin Lee, Department of Pharmaceutical Chemistry, School of Pharmacy,

International Medical University, No 126, Jalan 19/155B, Bukit Jalil, 57000, Kuala Lumpur, Malaysia 


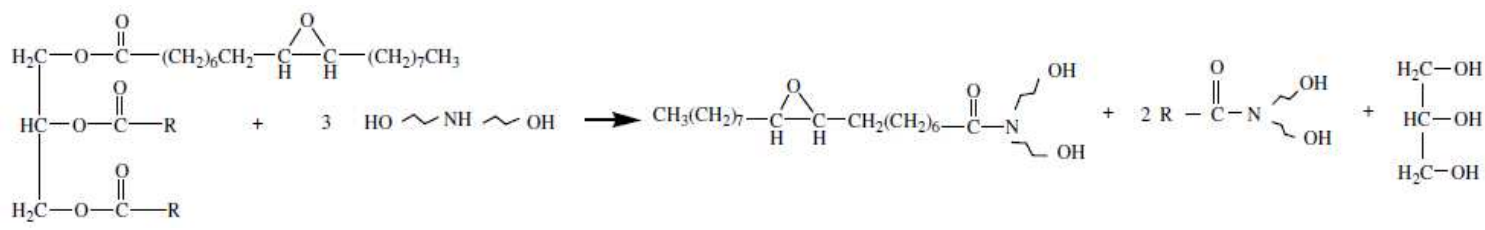

Fig. 1: Synthesis of epoxidized and non-epoxidized fatty diethanolamides

Common analyses are hydroxyl value determination, Fourier Transform Infrared spectroscopy (FTIR) and Thin Layer Chromatography (TLC) to determine the completion of the reaction (Badri et al., 2004; Rahman et al., 2003). Gel Permeation Chromatography (GPC) had been used to analyze the average molecular weight of the vegetable oil-based polyols (Badri et al., 2001). The chemical identification of the fatty diethanolamides by spectroscopy methods are not widely used. In this study, we used HPLC and GC chromatographic method followed by LC-MS and GCMS spectrometric method for the simultaneous analysis of fatty diethanolamides polyols.

\section{MATERIALS AND METHODS}

Materials: RBDPKOo (specifications: iodine value $=$ $26 \mathrm{mg} \mathrm{I}_{2} / 100 \mathrm{~g}$ sample, free fatty acid $\mathrm{s}=0.10 \mathrm{mg}$ $\mathrm{KOH} / \mathrm{g}$ sample, saponification value $=250 \mathrm{mg} \mathrm{KOH}$ $\mathrm{g}^{-1}$ sample) was obtained from Kempas Oil Sdn. Bhd. and EPOo (specifications: oxirane oxygen contents = $3.0 \%$, acidity $=1.1 \mathrm{mg} \mathrm{KOH} / \mathrm{g}$ sample, iodine value $=$ $0.65 \mathrm{mg} \mathrm{I}_{2} / 100 \mathrm{~g}$ sample) was obtained from the pilot plant of Advanced Oleochemicals Technology Division (AOTD) of Malaysian Palm Oil Board (MPOB). Reagents: Diethanolamine (DEA) (BASF), dimethylformamide (J.T. Baker), N, Obis(trimethylsilyl)-trifluoroacetamide, 98+\% (BSTFA) (ACROS ORGANICS), were used as purchased.

Synthesis of fatty diethanolamides: The reaction was carried out using a 1 litre Pyrex glass reaction flask submerged in a silicone bath. The reaction flask was equipped with a condenser, thermometer and a magnetic stirrer. $40 \% \mathrm{EPO}_{\mathrm{o}}(\mathrm{w} / \mathrm{w})$ was blended with $60 \%$ (w/w) RBDPKOo to react with DEA at molar ratio of 1:3 [palm oil Triacylglyceride (TAG): DEA]. The reaction was carried out at $110^{\circ} \mathrm{C}$ for $5 \mathrm{~h}$. The blend of starting materials and reaction condition were the optimal percentage and reaction condition based on previous study on the synthesis of fatty diethanolamides.

\section{HPLC analysis:}

Test samples: The samples were taken from the synthesis of fatty diethanolamides from $40 \%$ (w/w) EPOo and 60\% (w/w) RBDPKOo.
Validation: There were no standard for fatty diethanolamides, therefore secondary standards were synthesized from pure methyl esters, such as methyl laurate $\left(\mathrm{C}_{12: 0}\right)$, methyl myristate $\left(\mathrm{C}_{14: 0}\right)$, methyl palmitate $\left(\mathrm{C}_{16: 0}\right)$, methyl stearate $\left(\mathrm{C}_{18: 0}\right)$ and methyl oleic $\left(\mathrm{C}_{18: 1}\right)$. These esters were reacted with DEA at $110^{\circ} \mathrm{C}$ for $5 \mathrm{~h}$.

Instrument and condition: The HPLC system was equipped with a binary gradient pump, an automatic, three-line degasser, a column oven and an ELSD. Data were recorded and analysed using Windows-based Intuitive Software for Chromatography (Borwin, Version 1.2; JBMS Developments, Le Fontanil, France). A packed Inertsil ODS 3 column $(4.6 \times 250 \mathrm{~mm}$; GL science Inc, Rockford, IL) was used for separation. The column was maintained at $30^{\circ} \mathrm{C}$ and the mobile phase 87 used was a mixture of 95:5 Acetonitrile (ACN) and water at a flow rate of $0.5 \mathrm{~mL} \mathrm{~min}^{-1}$. The ELSD detector was set at $40^{\circ} \mathrm{C}$ and run under 2.3 bar air pressure. The sample solution (approximately $0.02 \mathrm{~g}$ in $10 \mathrm{~mL} \mathrm{CAN}$ ) was passed through a $0.45 \mu \mathrm{m}$ disc filter to an auto sampler vial. A aliquot of about $20 \mu \mathrm{L}$ was injected into the HPLC system.

LC-MS analysis: The analyses were performed on a Perkin Elmer LC-200 pump fitted with a Rheodyne $812520 \mu \mathrm{L}$ loop injector. The LC column was connected to a single quadrupole Perkin Elmer Sciex API 100 LC-Ms system equipped with a heated nebuliser interface. The separations were performed on a packed Inertsil ODS 3 column $(4.6 \times 250 \mathrm{~mm}$; GL Science Inc., Rockford, IL). The separation was carried out with acetonitrile-water at 95:5. The flow rate was set at $0.08 \mathrm{~mL} \mathrm{~min}^{-1}$ and $10 \mu \mathrm{L}$ of the sample was injected into the LC-MS system.

\section{GC analysis:}

Standard solutions: The samples were prepared by adding in $1 \mathrm{~mL}$ of DMF into $0.03 \mathrm{~g}$ samples to dissolve the samples, $0.1 \mathrm{~mL}$ Bis(Trimethyl Silyl)tri Fluoro Asetanida (BSTFA) was then added. The mixture was shake vigorously and warmed at $60^{\circ} \mathrm{C}$ for $15 \mathrm{~min}$ before analyzing by gas chromatography. This procedure allowed the silylation of the samples to take place. The sample was then transffered to a $2 \mathrm{~mL}$ autosampler vial for injection into the GC system. 
Instrument and condition: The SGE HT-5, Polymide clad, $12 \mathrm{~m} \times 0.53 \mathrm{mn} \times 0.15 \mu \mathrm{m}$ column was used in the gas chromatograph study. The injection was made at $80^{\circ} \mathrm{C}$, hold for $8 \mathrm{~min}$ and the temperature of the injector and column oven were raised by $5^{\circ} \mathrm{C} \min ^{-1}$ to $220^{\circ} \mathrm{C}$. The inlet temperature and the detector temperature were $250^{\circ} \mathrm{C}$. Helium gas was used as the carrier gas and the flow rate for the column was $27.0 \mathrm{~mL} \mathrm{~min}{ }^{-1}$. Nitrogen gas was used as the makeup gas.

GC-MS analysis: Mass spectrometric data was carried out on an Agilent 5973 Network Mass Selective detector interfaced to an Agilent 6890 Series gas chromatograph with a septum-equipped programmable Agilent 783 Series injector. The HP-5 ms column, 30 $\mathrm{m} \times 0.25 \mathrm{~nm}$ id, 0.25 micron $\mathrm{m}$ film was used in the gas chromatographic study and was connected directly to the Electron Impact (EI) source $(70 \mathrm{eV})$. The injection was made at $80^{\circ} \mathrm{C}$, hold for $50 \mathrm{~min}$ and the temperature of the injector and column oven was raised by $5^{\circ} \mathrm{C}$ $\mathrm{min}^{-1}$ to $270^{\circ} \mathrm{C}$. The inlet pressure of the helium carrier gas was $8.67 \mathrm{psi}$ and the flow rate was $1 \mathrm{~mL} \mathrm{~min}^{-1}$ with the MSD detector was used. The inlet temperature was $280^{\circ} \mathrm{C}$ whereas the auxiliary set point was $290^{\circ} \mathrm{C}$. The

samples were dissolved in THF and derivatized by BSTFA before analyzing by mass spectrometry.

\section{RESULTS}

Table 1 shows the retention time of the fatty diethanolamides by HPLC analysis. The analysis was continued by using LC-MS and the molecular weights of the fatty diethanolamides are shown in Table 2.

Table 1: Components of the diethanolamides and retention time by HPLC analysis

\begin{tabular}{ll}
\hline Component & Retention time (min) \\
\hline DEA & 5.6 \\
Decanoic acid bis-(2-hydroxy-ethyl)-amide / & 6.5 \\
C $_{10: 0}$ diethanolamide & \\
Dodecanoic acid bis-(2-hydroxy-ethyl)-amide/ & 8.9 \\
C $12: 0_{\text {diethanolamide }}$ & \\
Tetradecanoic acid bis-(2-hydroxy-ethyl)-amide/ & 11.8 \\
C $_{14: 0}$ diethanolamide & \\
Hexadecanoic acid bis-(2-hydroxy-ethyl)-amide/ & 16.3 \\
$\mathrm{C}_{16: 0}$ diethanolamide & \\
Octadec-9-enoicacid-bis-(2-hydroxy-ethyl)-amide/ & 17.2 \\
$\mathrm{C}_{18: 1}$ diethanolamide & \\
Octadecanoic acid bis-(2-hydroxy-ethyl)-amide/ & 23.6 \\
$\mathrm{C}_{18: 0}$ diethanolamide & \\
\hline
\end{tabular}

Table 2: Selected LC-MS fragment ions of the fatty 321 diethanolamides

\begin{tabular}{lll}
\hline Diethanolamides & Molecular weight of diethanolamides & Fragment ions (m/z) \\
\hline Decanoic acid bis-(2-hydroxy-ethyl)-amide & 259 & $488.5,323.0,282.5,260.0\left[(\mathrm{M}-\mathrm{H})^{+}, 100 \%\right], 142.0$ \\
Dodecanoic acid bis-(2-hydroxy-ethyl)-amide & 287 & $488.5,392.0,350.5,288.0\left[(\mathrm{M}-\mathrm{H})^{+}, 100 \%\right], 146.0$ \\
Tetradecanoic acid bis-(2-hydroxy-ethyl)-amide & 315 & $419.5,378.0,316.0\left[(\mathrm{M}-\mathrm{H})^{+}, 100 \%\right], 232.5,147.0$ \\
Hexadecanoic acid bis-(2-hydroxy-ethyl)-amide & 343 & $447.0,365.5,344.0\left[(\mathrm{M}-\mathrm{H})^{+}, 100 \%\right], 288.5,1147.0$ \\
Octadec-9-enoicacid-bis-(2-hydroxy-ethy 1)-amide & 369 & $472.5,391.0,370.0\left[(\mathrm{M}-\mathrm{H})^{+}, 100 \%\right], 217.5,1147.0$ \\
Octadecanoic acid bis-(2-hydroxy-ethyl)-amide & 371 & $472.5,393.5,372.0\left[(\mathrm{M}-\mathrm{H})^{+}, 100 \%\right], 288.5,1146.0$ \\
\hline
\end{tabular}

Table 3: Composition of trimethylsilyl derivatives of fatty diethanolamides and 351 retention time

\begin{tabular}{|c|c|c|}
\hline Component & Retention time (min) & w/w $(\%)$ \\
\hline Glycerol & 0.846 & 21.76 \\
\hline DEA & 1.554 & 0.79 \\
\hline Unknown & 2.383 & 0.28 \\
\hline $\mathrm{C}_{12}$ fatty acid & 2.984 & 1.26 \\
\hline Unknown & 4.065 & 0.48 \\
\hline $\mathrm{C}_{14}$ fatty acid & 4.729 & 0.21 \\
\hline $\mathrm{C}_{6}$ diethanolamide & 5.155 & 0.20 \\
\hline $\mathrm{C}_{16}$ fatty acid & 6.356 & 0.76 \\
\hline $\mathrm{C}_{8}$ diethanolamide & 6.744 & 2.34 \\
\hline Monolauroyl glycerol & 7.996 & 0.85 \\
\hline $\mathrm{C}_{10}$ diethanolamide & 8.262 & 1.68 \\
\hline Unknown & 9.200 & 0.52 \\
\hline Unknown & 9.375 & 0.45 \\
\hline $\mathrm{C}_{12}$ diethanolamide & 9.847 & 19.46 \\
\hline Unknown & 10.736 & 0.27 \\
\hline $\mathrm{C}_{14}$ diethanolamide & 11.109 & 6.22 \\
\hline Unknown & 11.809 & 0.26 \\
\hline $\mathrm{C}_{16}$ diethanolamide & 12.447 & 13.53 \\
\hline $\mathrm{C}_{18: 2}+\mathrm{C}_{18: 1}$ diethanolamide & 13.395 & 9.28 \\
\hline $\mathrm{C}_{18: 0}$ diethanolamide & 13.564 & 2.10 \\
\hline 8-(3-octyl-oxiranyl)-octanoic acid bis-(2-hydroxy-ethyl)-amide & 14.513 & 8.38 \\
\hline Unknown & 14.670 & 0.23 \\
\hline Dilauroyl glycerol & 15.166 & 1.03 \\
\hline 8-[3-(3-Pentyl-oxiranylmethyl)-oxiranyl]-octanoic acid bis-(2-hydroxy-ethyl)-amide & 15.454 & 1.11 \\
\hline Unknown & 16.628 & 0.50 \\
\hline Dimyristoyl glycerol & 16.738 & 0.44 \\
\hline Dipalmitoyl glycerol & 17.833 & 4.38 \\
\hline Unknown & 18.198 & 0.89 \\
\hline Unknown & 18.397 & 0.34 \\
\hline
\end{tabular}


Am. J. Pharm. \& Toxicol., 5 (3): 133-138, 2010

Table 4: Selected GC-MS fragment ions of trimethylsilyl derivatives of 362 diethanolamides

\begin{tabular}{|c|c|c|c|}
\hline Trimethylsilyl derivatives of diethanolamide polyols & Retention time (min) & Molecular weight $\left(\mathrm{g} \mathrm{mol}^{-1}\right)$ & Fragment ions, $\mathrm{m} / \mathrm{z}$ \\
\hline $\begin{array}{l}\mathrm{N}, \mathrm{N} \text {-bis(2-(trimethylsilyloxy) } \\
\text { ethyl)hexanamide }\end{array}$ & 24.51 & 347 & $\begin{array}{l}347(\mathrm{M}+\mathrm{TMS})^{+} \\
332,214,146,73\end{array}$ \\
\hline $\begin{array}{l}\text { N,N-bis(2-(trimethylsilyloxy) } \\
\text { ethyl)octanamide }\end{array}$ & 27.99 & 375 & $\begin{array}{l}375(\mathrm{M}+\mathrm{TMS})^{+} \\
360,242,146,73\end{array}$ \\
\hline $\begin{array}{l}\text { N,N-bis(2-(trimethylsilyloxy) } \\
\text { ethyl)decanamid }\end{array}$ & 31.30 & 403 & $\begin{array}{l}403(\mathrm{M}+\mathrm{TMS})^{+} \\
388,270,146,73\end{array}$ \\
\hline $\begin{array}{l}\text { N,N-bis(2-(trimethylsilyloxy) } \\
\text { ethyl)dodecanamide }\end{array}$ & 34.43 & 431 & $\begin{array}{l}431(\mathrm{M}+\mathrm{TMS})^{+} \\
416,298,146,73\end{array}$ \\
\hline $\begin{array}{l}\text { N,N-bis(2-(trimethylsilyloxy) ethyl) } \\
\text { Tetradecanamide }\end{array}$ & 37.33 & 459 & $\begin{array}{l}459(\mathrm{M}+\mathrm{TMS})^{+} \\
444,326,146,73\end{array}$ \\
\hline $\begin{array}{l}\text { N,N-bis(2-(trimethylsilyloxy) } \\
\text { ethyl)palmitamide }\end{array}$ & 40.08 & 487 & $\begin{array}{l}487(\mathrm{M}+\mathrm{TMS})^{+} \\
472,354,146,73\end{array}$ \\
\hline $\begin{array}{l}\text { N,N-bis(2-(trimethylsilyloxy) } \\
\text { ethyl)octadec-9-enamide }\end{array}$ & 42.31 & 513 & $\begin{array}{l}513(\mathrm{M}+\mathrm{TMS})^{+} \\
498,380,146,73\end{array}$ \\
\hline $\begin{array}{l}\mathrm{N}, \mathrm{N}-\text { bis(2-(trimethylsilyloxy) } \\
\text { ethyl)stearamide }\end{array}$ & 42.64 & 515 & $\begin{array}{l}515(\mathrm{M}+\mathrm{TMS})^{+} \\
500,382,146,73\end{array}$ \\
\hline $\begin{array}{l}\text { 8-(3-octyl-oxiran-2-yl)-N,N-bis( } 2 \\
\text { (trimethylsilyloxy)ethyl)octanamide }\end{array}$ & 44.99 & 529 & $\begin{array}{l}529(\mathrm{M}+\mathrm{TMS})^{+} \\
514,396,146,73\end{array}$ \\
\hline $\begin{array}{l}\text { 8-(3-(3-pentyloxiran-2- } \\
\text { yl)methyl)oxiran-2-yl)-N,N-bis(2-(trimethy } \\
\text { lsilyloxy)ethyl)octanamide }\end{array}$ & 47.55 & 543 & $\begin{array}{l}543(\mathrm{M}+\mathrm{TMS})^{+} \\
528,410,146,73\end{array}$ \\
\hline
\end{tabular}

Table 3 summarizes the composition and retention time of trimethylsilyl derivatives of fatty diethanolamides, glycerol, DEA, monoglycerides, diglycerides and some minor unknown compounds. Table 4 shows the results of GC-MS analysis by showing the selected GC-MS fragment ions of trimethylsilyl derivatives of diethanolamides.

\section{DISCUSSION}

HPLC and LC-MS analyses: To date, the characterization of diethanolamides using HPLC and LC-MS analyses have not been reported yet. Therefore, this study attempted to use a compatible solvent, Acetonitrile (ACN), to dissolve the sample for HPLC analysis. As the diethanolamides consisted of hydroxyl and amide groups that are rather polar, the solvent system of 90:10 (ACN: water) was the most suitable for use in the separation. When the fatty diethanolamide mixtures are analyzed, the retention time between the products and the prepared secondary standards was comparable and most of the major diethanolamide compounds, namely $\mathrm{C}_{10: 0}, \mathrm{C}_{12: 0}, \mathrm{C}_{14: 0}, \mathrm{C}_{16: 0}, \mathrm{C}_{18: 1}$ and $\mathrm{C}_{18: 0}$ were successfully identified as in Table 1. Subsequent characterization of the diethanolamides was continued using LC-MS analysis and the molecular weight of the products were identified (Table 2). HPLC is a convenient method in separation of fatty diethanolamides by only dissolving the samples with mobile phase without any derivatization. However, only non-epoxidized fatty diethanolamides were identified by HPLC analysis, the separation was still not complete. Different solvent systems, condition of the system had been modified; unfortunately the epoxidized fatty diethanolamides were still failed to separate. Studies may be continued in future by using other type of columns.

GC and GC-MS analyses: GC method has been reported not only in separating diethanolamides products (O'Connell, 1977) but also in obtaining better results when compared with the HPLC method in analyzing palm oil-based polyol esters (Yunus et al., 2002). Thus, GC method was attempted in order to obtain a better and comprehensive separation of the diethanolamide mixtures. A number of organic solvents were used to dissolve the synthesized diethanolamides. Results showed that DMF and THF were the most suitable solvents. The fatty diethanolamides with hydroxyl and amide functionalities are rather polar with low volatility and hence were converted to the less polar trimethylsilyl derivatives prior to injection. Piekos and co-workers reported the conversion of ethanolamines to trimethylsilyl derivatives before gas chromatographic determination by reacting the monoethanolamines, diethanolamines and triethanolamines with $\mathrm{N}, \mathrm{O}-\mathrm{bis}($ trimethylsilyl)acetamide (BSA) (Piekos et al., 1975). In this study, N,Obis(trimethylsilyl)-trifluoroacetamide (BSTFA) was used to convert diethanolamides to the trimethylsilyl diethanolamide products. The retention time between the products and the prepared secondary standards was comparable and most of the trimethylsilyldiethanolamides, namely $\mathrm{C}_{6: 0}, \mathrm{C}_{8: 0}, \mathrm{C}_{10: 0}, \mathrm{C}_{12: 0}, \mathrm{C}_{14: 0}$, 
$\mathrm{C}_{16: 0}, \mathrm{C}_{18: 2}, \mathrm{C}_{18: 1}, \mathrm{C}_{18: 0}$, epoxidized $\mathrm{C}_{18: 1}$ and epoxidized $\mathrm{C}_{18: 2}$ diethanolamides, were successfully identified. Besides, Glycerol, DEA, fatty acids, monoglycerides and diglycerides were also identified (Table 3). The percentage of the fatty diethanolamide products and glycerol by-products contained in the sample were 64.30 and $21.76 \%$; respectively. Some unknown compounds $(3.22 \%)$ were detected in the product mixtures. These unknown compounds were most likely diesteramine, N,N-bis(2-hydroxyethyl) piperazine(I), monoesteramine, monoesteramide or diesteramide produced from the self-condensation of DEA and diethanolamide products at elevated temperature (Trowbridge et al., 1955). This observation was consistent with the report on condensation of coconut oil with DEA that yielded $2.8 \%(\mathrm{w} / \mathrm{w})$ of diesteramine by-products through gas chromatographic analysis (O'Connell, 1977). The molecular weight and structure of the trimethylsilyl-173 derivatized diethanolamides were further characterized using GCMS analysis (Table 4) The molecular ion (M+TMS) ${ }^{+}$. For the epoxidized diethanolamides, namely 8-(3octyl-oxiranyl)-octanoic acid bis-(2trimethylsilanyloxyl-ethyl)-amide and 8-[3-(3-Pentyloxiranylmethyl)- oxiranyl]-octanoic acid bis-(2trimethylsilanyloxyl-ethyl)-amide, were recorded at 529 and $543 \mathrm{~m} / \mathrm{z}$ respectively. GC and GC-MS analyses gave complete separation to the reaction mixture containing epoxidized and non-epoxidized fatty diethanolamides. These chromatographic methods are more suitable to be used in monitoring the products of the reaction. The only disadvantage for this method is the conversion of fatty diethanolamides to trimethylsilyl derivatives prior to injection.

\section{CONCLUSION}

HPLC and LCMS analyses can be used to analyze fatty diethanolamides from the synthesis of natural triacylglycerols with diethanolamine. GC and GC-MS analyses provide a more complete separation to fatty diethanolamide mixture with epoxidized and nonepoxidized fatty diethanolamides. These chromatographic and spectrometric methods are suitable for reaction monitoring, particularly reactions involving epoxidized oil.

\section{ACKNOWLEDGEMENT}

This study was supported by the Malaysian Palm Oil Board Graduate Research Grant.

\section{REFERENCES}

Badri, K.H., S.H. Ahmad and S. Zakaria, 2001. The production of a high-216 functionality RBD palm kernel-based polyester polyol. J. Applied Polymer Sci., 82: 827-832. DOI: 10.1002/app.1913

Badri, K.H., Z. Othman and S.H. Ahmad, 2004. Rigid polyurethane foams from oil palm resources. J. Mater. Sci., 39: 5541-5542. DOI: 10.1023/B:JMSC.0000039282.86374.fc

Bononi, M. and F. Tateo, 2007. Identification of perfluorooctanoic acid release from commercial coated cooking pans by liquid chromatography coupled to electrospray ionization tandem mass spectrometry. Am. J. Agric. Biol. Sci., 2: 191-194. http://www.scipub.org/fulltext/AJAB/AJAB23191194.pdf

Feairheller, S.H., R.G. Bistline, A. Bilyk, R.L. Dudley and M.F. Kozempel et al., 1994. A novel technique for the preparation of secondary fatty amides. III. Alkanolamides, diamides and arylamides. J. Am. Oil Chem. Soc., 71: 863-866. DOI: 10.1007/BF02540463

Khoe, T.H and E.N. Frankel, 1976. Rigid polyurethane foams from diethanolamides of carboxylated oils and fatty acids. J. Am. Oil Chem. Soc., 53: 17-19. DOI: $10.1007 / \mathrm{BF} 02632517$

Khoe, T.H., F. Otey, E.N. Frankel and J.C. Cowan, 1973. Polyurethane foams from hydroxymethylated fatty diethanolamides. J. Am. Oil Chem. Soc., 50: 331-333. DOI: 10.1007/BF02641367

Kolancilar, H., 2004. Preparation of laurel oil alkanolamide from laurel oil. J. Am. Oil Chem. Soc., 81: 597-598. DOI: 10.1007/s11746-0060947-y

Lee, C.S., T.L. Ooi, C.H. Chuah and S. Ahmah, 2007. Rigid polyurethane foam production from palm oilbased epoxidized diethanolamides. J. Am. Oil Chem. Soc., 84: 1161-1167. DOI: 10.1007/s11746007-1150-5

Lee, C.S., T.L. Ooi and C.H. Chuah, 2009. The effect of reaction temperature on retaining oxirane oxygen contents in the synthesis of epoxidized diethanolamides. Am. J. Applied Sci., 6: 72-77. http://www.scipub.org/fulltext/ajas/ajas6172-77.pdf

O'Connell, A.W., 1977. Analysis of coconut oildiethanolamine condensates by gas chromatography. Anal. Chem., 49: 835-838. DOI: 10.1021/ac50014a042

Piekos, R., K. Kobylczyk and J. Grzybowski, 1975. Quantitative gas chromatographic determination of ethanolamines as trimethylsilyl derivatives. Anal. Chem., 47: 1157-1159. DOI: 10.1021/ac60357a030 
Rahman, M.B.A., C.L. Yap, K. Dzulkefly, R.N.Z. Abdul Rahman and A.B. Salleh et al., 2003. Synthesis of palm kernel oil alkanolamide using lipase. J. Oleo Sci., 52: 65-72. http://www.jstage.jst.go.jp/article/jos/52/2/65/_pdf

Shapiro, S.H., 1968. Commercial Nitrogen Derivative of Fatty Acids. In: Fatty Acids and their Industrial Applications, Pattison, E.S. (Ed.). Marcell Dekker Inc., New York, ISBN: 0713160608, pp: 77-154.
Trowbridge, J.R., R.A. Falk and I.J. Krems, 1955. Fatty acid derivatives of diethanolamine. J. Org. Chem., 20: 990 995. DOI: 10.1021/jo01365a005

Yunus, R., T.L. Ooi, A. Fakhru'l-Razi and S. Basri, 2002. A simple capillary column GC method for analysis of palm oil-based polyol ester. J. Am. Oil Chem. Soc., 79: 1075-1080. DOI: 10.1007/s11746002-0606-3 